\title{
MORTALITY OF HANFORD RADIATION WORKERS
}

By

\author{
Ethel S. Gilbert
}

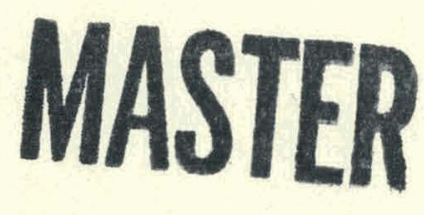

\begin{abstract}
Statistics Section
Energy Systems Department Pacific Northwest Laboratory Battelle Memorial Institute

Richland, WA 99352
\end{abstract} This book was prepared as an account of work sponsored by an agency of the United States Government.
Neither the United States Government nor any agency thereof, nor any of their employees, makes any warranty, express or imolied, or assumes any legal liability or responsibility for the accuracy. completeness, or usefuiness of any information. apparatus, product, or process disclosed, or

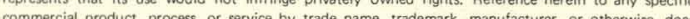

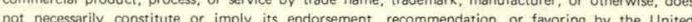
States Government or any agency thereof. The views and opinions of a athors expressed herein do not

Prepared for the U.S. Department of Energy under Contract EY-76-C-06-1830. 


\section{DISCLAIMER}

This report was prepared as an account of work sponsored by an agency of the United States Government. Neither the United States Government nor any agency Thereof, nor any of their employees, makes any warranty, express or implied, or assumes any legal liability or responsibility for the accuracy, completeness, or usefulness of any information, apparatus, product, or process disclosed, or represents that its use would not infringe privately owned rights. Reference herein to any specific commercial product, process, or service by trade name, trademark, manufacturer, or otherwise does not necessarily constitute or imply its endorsement, recommendation, or favoring by the United States Government or any agency thereof. The views and opinions of authors expressed herein do not necessarily state or reflect those of the United States Government or any agency thereof. 


\section{DISCLAIMER}

Portions of this document may be illegible in electronic image products. Images are produced from the best available original document. 


\section{INTRODUCTION}

Assessing the health effects of chronic low-level exposures to radiation poses a number of challenging problems in analysis. Many of these problems are well illustrated by a current study of the effects on mortality of occupational exposure to ionizing radiation at the Hanford plant.

The Hanford plant, which is located in southeastern Washington, was established in the early forties as an installation for plutonium production. Many of the workers employed by the various contractors hold jobs involving some exposure to radiation. Yearly records of this exposure, obtained from dosimeter readings, as well as occupational data, are maintained for all employees. Mortality data are obtained by having the Social Security Administration periodically search their records for deaths of persons identified in the personnel rosters of Hanford contractors.

\section{COMPARISON WITH U.S. MORTALITY}

The analysis that I will emphasize in this presentation is one in which death rates are related to exposure status. However, to provide perspective on the magnitude of the death rates involved, the rates for Hanford workers are also compared with those of the U.S. population. To carry out this comparison, we calculated standardized mortality ratios (SMR's) which indicate in percentage form the ratio of deaths observed in the population under consideration to the deaths expected in the same population if U.S. rates prevail $(100 \times$ observed deaths $\div$ expected deaths). Expected deaths are calculated in a way that takes the age and calendar year distribution of the population of interest into account. We used a computer program developed by Monson, who has provided a more complete description of the method of calculation and of the program [13]. In this 
presentation, I will briefly summarize the major results of this analysis for 13,075 white males employed at Hanford at least two years. For additional detail see $[10]$.

The number of observed deaths from all causes is $75 \%$ of that which would be expected based on age-calendar year specific rates for U.S. white males. This low SMR is fairly typical of an employed population [11] since persons considered poor health risks are screened out during pre-employment examinations. This selective bias is sometimes referred to as the "healthy worker effect." The health of Hanford employees may be favorably affected by a program of medical surveillance, including periodical physical examinations. Some deaths may also be missed by the Social Security Administration. (One estimate of the percentage of deaths missed in this manner is $6 \%$ [14].)

McMichael [11] and Enterline [3] have noted that the selective bias involved in the healthy worker effect is generally less for deaths from malignant neoplasms than from other causes such as circulatory and respiratory disease. This is exhibited in the longer term Hanford workers by an SMR of $85 \%$ for malignant neoplasms.

We also calculated SMR's for 22 specific cancer types. In no case did we find that the number of deaths observed in this population significantly exceeded the number of deaths expected based on U.S. rates. It is particularly relevant that leukemia was not found to be excessive since this is the disease that has been most strongly associated with radiation in other studies, such as the Japanese survivors, for example.

\section{RADIATION EXPOSURE DATA}

Figure 1 shows the distribution of doses accumulated through 1973 for monitored white males employed at Hanford at least two years. The highly skewed 
nature of the distribution reflects the fact that most Hanford workers are not regularly involved in radiation work so that only a relatively small number of workers (less than $15 \%$ of the work force) receive annual whole body doses in excess of 1 rem with a very small number of these exceeding 4 rem per year (less than $1 \%$ of the work force).

Radiation exposure is correlated with a number of variables that may also affect mortality. Calendar year, in particular, is very highly correlated with exposure because few doses over 1 rem were received during the early period of plant operation and because it takes a number of years to accumulate a substantial dose. This is especially important with respect to lung cancer since U.S. rates from this cause have nearly doubled between 1950 and 1970 [18].

Most of the higher exposures were received by workers in a few specific occupations, all classified as craftsmen or operators. These workers may have smoking habits* and occupational exposures (other than radiation) which differ from the remainder of the Hanford population. Since it has been demonstrated that occupation and its associated socio-economic status can affect, mortality [14], it is important to consider this factor in our analys is.

\section{EXPOSURE ANALYSIS}

The exposure analysis included 12,552 monitored white males who were employed at Hanford at least two years and who were still alive at the beginning of 1955. Short term workers (less than two years) were exciuded because for the most part they have received little radiation exposure. Their inclusion could bias the analysis because they have been less subject to the factors that

*Unfortunately, we do not have data on the smoking habits of Hanford workers. 
contribute to the heal thy worker effect described above. Eliminating the short term workers excluded no male deaths with exposure exceeding 5 rem and only two cancer deaths with exposures between 2 and 5 rem (a lung cancer and lymphosarcoma).

The basic method of analys is was to categorize workers at a given time and then compare the subsequent mortality experience of the various exposure groups. Only past exposure for a stated time is included since future exposure would be correlated with survival--that is, the longer one survives the more opportunity one has to accumulate exposure. For a more detailed description of the method used see [4] and [10].

The four exposure groups considered are <2 rems, 2-5 rems, 5-15 rems, and 15 or more rems. The Mantel-Haenszel method [8] was used to calculate expected deaths. That is, the combined experience of all four groups was used to calculate the number of deaths expected in each dose group if mortality rates were not affected by radiation exposure. Rates for the U.S. population:were not used here. The calculation of expected deaths was done in a way that adjusted for age (in 5-year intervals), for occupation (by separating craftsmen and operators from the remaining occupations), for calendar year (in single years from 1955 to 1974), and employment status (by separating employed and terminated years).

\section{RESULTS AND DISCUSSIONS OF EXPOSURE ANALYSIS}

In Table 1 the observed and expected deaths for the four exposure categories and results of the test for trend are presented for all causes of death, all cancer, and several specific cancer types. Recall that the calculation of the expected deaths was based on the assumption of no radiation effect and did not involve the use of an external population. Thus the sum of expected deaths across exposure categories must necessarily equal the sum of observed deaths, and 
a deficiency of deaths in one exposure category necessarily implies an excess in some other category. A positive correlation of mortality and radiation exposure is indicated by a generally increasing ratio of observed to expected deaths with increasing exposure. Significance levels were obtained using Mantel's test for trend [9].

The cause of death which has been most strongly associated with radiation exposure in other studies $[1,17]$ is myeloid leukemia. With a single death observed in the 5-15 rem group and 0.6 deaths expected in the top two exposure groups, we cannot conclude that there is an association between radiation exposure and leukemia in the Hanford population.

These other studies have also found an excessive number of deaths due to all cancers among those with high radiation exposures. There is no evidence of such an effect in the Hanford population. In the top two exposure groups there are 32 cancer deaths observed compared with 38.3 expected. When deaths from all causes are examined, there are fewer deaths observed than expected in the top two exposure groups.

- It is important to note that the above findings are not inconsistent with current estimates of health effects from low-level exposure to radiation. Such estimates have been obtained by linear extrapolation from effects at high level exposures such as those experienced by atomic bomb survivors at Hiroshima and Nagasaki and by British patients treated with irradiation for ankylosing spondylitis. If these estimates are correct, it is unlikely that statistically detectable effects will be identified in occupationally exposed populations such as Hanford workers. The study of such groups nevertheless provides an opportunity for evaluating the hypothesis that effects might be very much larger than indirect estimates would suggest. 
There are two cancer sites for which the number of deaths observed in the higher exposure groups exceeds that expected. These are multiple myeloma for which we have 3 deaths observed in the highest exposure group compared with half a death expected, and cancer of the pancreas for which we have 3 deaths observed compared with 1 expected. The multiple myeloma correlation is significant at the $1 \%$ level while the cancer of the pancreas correlation is somewhat borderline with a significance level between 5 and 10 percent. These results are of course based on a very small number of deaths.

An interesting aspect of these findings is the particular sites which exhibit correlations. Although there is some evidence from other studies that multiple myeloma and cancer of the pancreas have been induced by radiation, it is not nearly as substantial as that for certain other cancer types, myeloid. leukemia being the most noteworthy example. Nearly every study which has shown evidence of a radiation effect has shown it most strongly for leukemia.

A possible explanation of these findings is that chronic low-level exposure to radiation (such as Hanford workers have experienced) manifests itself differently from the acute exposure. This explanation has to be given serious consideration since most other studies of radiation exposure have been based on acute, high level exposures.

There are other explanations. First, when several statistical tests are performed (15 cancer sites were tested), false positive results are not unusual. Second, it is possible that some other factor, perhaps another occupational exposure that is correlated with radiation, is the true cause of these deaths. Unfortunately, information on other exposures at Hanford (certain operations involve chemical exposure of various types) is not nearly as complete as information on radiation exposure. 
In addition to the analysis described above, we have also considered the effect of lagging exposures for various periods, of various combinations of stratification variables, and of the use of mean doses (rather than grouped exposures). None of these additional analyses provided any indication that all cancers combined or any specific cancer (other than multiple myeioma and cancer of the pancreas) were positively correlated with radiation exposure.

\section{OTHER ANALYSES OF THE HANFORD DATA}

The Hanford data has been analyzed recently by Mancuso, Stewart and Kneale $[5,7]$. Since-their conclusion that there is a causal relationship between radiation exposure and several cancer types is not supported by the analys is presented here, it seems appropriate to comment briefly on the differences in the two approaches. In the analysis of these investigators, mean cumulative exposures for all cancer deaths and for several cancer types were compared with mean exposures for deaths from causes other than cancer for several predeath intervals. Mancuso, Stewart and Kneale found statistically significant differences (using a t-test) for all cancer deaths, bone marrow cancers (including myeloid leukemia and multiple myeloma), cancer of the pancreas and lung cancer.

Our analysis confirms the correlation of radiation exposure with multiple myeloma and cancer of the pancreas, although we have reservations as to whether the associations result from cause and effect relationships. Myeloid leukemia, considered alone, does not exhibit any association with radiation exposure, a point which is obscured by Mancuso, Stewart and Kneale's unorthodox grouping of myeloid leukemia and multiple myeloma. The inference for bone marrow cancer rests entirely on three high exposure deaths from multiple myeloma. In principal studies in which effects of whole body radiation exposure have been 
demonstrated in man, the most striking result has been the increase in mortality from myeloid leukemia. Thus, the lack of such an effect in the Hanford population is an important finding which not only deserves mention, but colors the interpretation of other findings.

In calculating means and doubling doses for various cancer sites, Mancuso, Stewart and Kneale gave no attention to age at death, calendar year of death, length of employment, and occupation. Failure to account for year of death is responsible for the association of radiation and lung cancer noted by these authors. The mean radiation dose for workers dying after 1970 is more than four times that for workers dying before 1960 while lung cancer death rates for U.S. White males have more than doubled between 1950 and 1975 [18]. When control for calendar year is added as in our analysis or as in [5], no correlation of radiation and lung cancer is found.

With data that is as extraordinarily skewed as the cumulative radiation exposures (see Figure 1) and with sample sizes that are frequently very smal1, one or two large doses can greatly inflate the mean and exaggerate significance levels obtained from the t-statistic. One or two large doses can also have a large impact on the doubling doses and result in subsequent over-estimation of the number of radiation induced cancers.

For additional criticism of the Mancuso, Stewart and Kneale analysis, the reader is referred to Hutchison, et al. [5], Anderson [2], Mole [12], Reissland [15], and Sanders [16].

\section{SUMMARY AND CONCLUSIONS}

Mortality from all causes for white males employed at Hanford for at least two years is $75 \%$ of that expected on the basis of U.S. vital statistics. Mortality from cancer is $85 \%$ of that expected. These results are typical of a 
working population. Neither death from all causes nor death from all cancer types shows a positive correlation with external radiation exposures. Myeloid leukemia, the disease that several studies have found to be associated most strongly with radiation exposure, is not correlated with external radiation exposure of Hanford workers. These results are not, however, inconsistent with current estimates of radiation effects.

Two specific cancers, multiple myeloma and to a lesser extent cancer of the pancreas, were found to be positively correlated with radiation exposure. While these associations warrant continued attention, in the absence of a priori grounds for expecting these particular two sites to exhibit correlations, we cannot rule out the possibility that one or both correlations may be false positive results ( 15 cancer sites were tested). It must also be kept in mind that other occasional exposures may have played a confounding role and that death certificate diagnosis of cancer of the pancreas is not very reliable. The correlations identified result entirely from a small number of deaths ( 3 each for multiple myeloma and cancer of the pancreas) with cumulative exposure greater than 15 rem.

Observation and analysis will be continued in the future to check further our current findings and monitor any new developments that might occur in this employee population. 


\section{REFERENCES}

1. Advisory Committee on the Biological Effects of Ionizing Raditions, National Academy of Sciences-National Research Council, The Effects on Populations of Exposure to Low Levels of Ionizing Radiation, U.S. Government Printing Office, Washington, DC, 1972.

2. T. W. Anderson, Radiation exposures of Hanford workers: a critique of the Mancuso, Stewart and Kneale report, Health Physics 35:743-750, 1978.

3. P. E. Enterline, Pitfalls in epidemiological research. J. Occup. Med. 18:150-156, 1976.

4. E. S. Gilbert, The assessment of risks from occupational exposure to ionizing radiation. Proceedings of the SIMS 1978 Research Applications Conference on Energy and Health, June 1978 (in press).

5. G. B. Hutchison, S. Jabion, C. E. Land, and B. MacMahon, Review of report by Mancuso, Stewart, and Kneale of Radiation Exposure of Hanford Workers. Accepted for publication in Health Physics.

6. T. F. Mancuso, A. Stewart, and G. Kneale, Radiation exposures of Hanford workers dying from cancer and other causes. Health Physics 33:369-385, 1977.

7. G. W. Kneale, A. Stewart, and T. F. Mancuso, Reanalys is of data relating to the Hanford study of cancer risks of radiation workers, IAEA-SM-224/510, to be published in the Proceedings of the IAEA Symposium on Late Biological Effects of Ionizing Radiation held in Vienna, Austria, March 13-17, 1978.

8. N. Mantel and $W$. Haenszel, Statistical aspects of the analysis of data from retrospective studies of disease. J. Nat1. Cancer Inst. 22:719-748, 1958.

9. N. Mantel, Chi-square tests with one degree of freedom. Extentions of the Mantel-Haenszel procedure. J.Amer. Statistical Assoc. 58:690-700, 1963.

10. S. Marks, E. S. Gilbert, and B. D. Breitenstein, Cancer mortality in Hanford workers; IAEA-SM-224/509, to be published in Vol. 1, 369-386, of the Proceedings for the IAEA Symposium on Late Biological Effects of Ionizing Radiation, Vienna, Austria, March 13-17, 1978.

11. A. J. McMichael, Standardized mortlity ratios and the "healthy worker effect": scratching beneath the surface. J. Occup. Med. 18:165-168, 1976.

12. R. Mole, letter to the Lancet, The Lancet, 1155, 1978.

13. R. R. Monson, Analysis of realtive survival and proportional mortality. Comput. Biomed. Res. 7:325-332, 1974.

14. M. G. Ott, B. B. Holder, and R. R. Langer, Determinants of mortality in an industrial population. J. Occup. Med 18:171-177, 1976. 
15. J. A. Reissland, An assessment of the Mancuso study, National Radiological Protection Board document NRPB-R79, September 1978.

16. B. S. Sanders, Low level radiation and cancer deaths. Health Physics $34: 521-538,1978$.

17. Sources and Effects of Ionizing Radiation. UN Scientific Committee on the effects of Ionizing Radiation report to the General Assumbly, with Annexes, "Radiation carcinogenes is in man," pp. 361-423, UN, New York, 1977.

18. 1977 Cancer Facts and Figures. American Cancer Society, New York, 1976. 


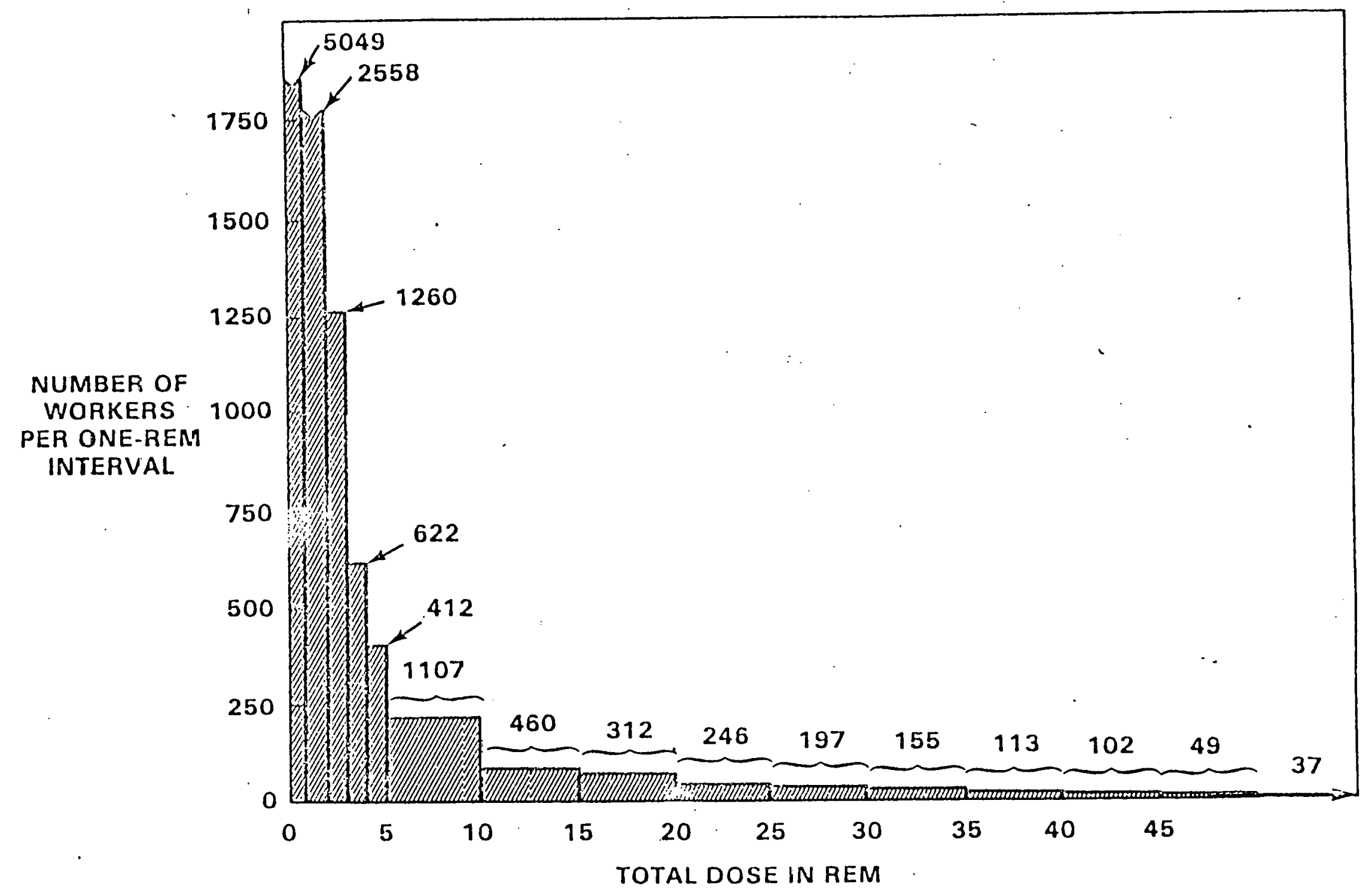

FIG. 1. DISTRIBUTION OF CUMULATIVE DOSES FOR WHITE MALE WORKERS EMPLOYED AT LEAST TWO YEARS 
Updated Table VIII ${ }^{\mathrm{e}}$. (Includes deaths up to May 1, 1977)

observed and expected deaths due to selected causes by exposure catecory for monitored white males employed at least two years. Exposures are lagged for two years (see text).

\begin{tabular}{|c|c|c|c|c|c|c|c|c|c|c|c|}
\hline \multirow{2}{*}{$\frac{\text { Person Years }}{\text { Cause of Death }}$} & \multicolumn{2}{|c|}{$\begin{array}{l}0-\tilde{c} \mathrm{rem} \\
17 \lesssim, 254\end{array}$} & \multicolumn{2}{|c|}{$\begin{array}{r}2-5 \text { rem } \\
32,653\end{array}$} & \multicolumn{2}{|c|}{$\begin{array}{l}5-15 \text { rem } \\
21,609\end{array}$} & \multicolumn{2}{|c|}{$\begin{array}{l}15+\text { rem } \\
11,159\end{array}$} & \multicolumn{2}{|c|}{$\begin{array}{l}\text { Exposure } \\
\text { Score for } \\
\text { Irend Test }\end{array}$} & \multirow[t]{2}{*}{$\begin{array}{l}\text { of Irend } \\
\text { Aris ing Ope } \\
\text { to Chance }\end{array}$} \\
\hline & Obs. & Exp. ${ }^{\circ}$ & obs. & Exp. & obs. & Exp. & Obs. & Exp.1 & $\underline{\text { obs. }}$ & Exp. & \\
\hline All Causes & 1719 & 1707.7 & 263 & 261.3 & 144 & 147.8 & 90 & 99,2 & 2.4 & 2.5 & 0.88 \\
\hline All Malignant Neopl'asms $(140-209)^{c}$ & 342 & 344.6 & 66 & 56.1 & 29 & 32.8 & 20 & 23.5 & 2.5 & 2.7 & 0.81 \\
\hline M.N. of Buccal Cavity $(140-149)$ & 15 & 13.2 & $\mathbf{0}$ & 1.9 & 2 & 1.0 & 0 & 0.8 & 1.5 & 2.5 & 0.81 \\
\hline M.N. of Stomach (151) & 21 & 21.8 & 4 & 3.0 & 0 & 1.9 & 3 & 1.3 & 3.6 & 2.6 & 0.13 \\
\hline M.N. of Large Intestine (153) & 34 & 34.9 & 7 & 4.7 & 1 & 2.1 & 1 & 1.3 & 1.8 & 2.0 & 0.66 \\
\hline M.N. of Pancreas (157) & 21 & 22.9 & 6 & 4.5 & 1 & 2.9 & 4 & 1.8 & 4.4 & 3.0 & $>0.06$ \\
\hline $\begin{array}{r}\text { M.N. of Other Dicestive Organs } \\
(15 C, 152,155-6)\end{array}$ & 30 & 27.5 & 3 & 3.0 & 0 & 1.5 & 0 & 1.0 & 0.8 & 1.9 & $>0.95$ \\
\hline M.N. of Lung (16i) & 91 & 98.4 & 24 & 18.6 & 16 & 11.9 & 7 & 9.1 & 3.2 & 3.3 & 0.54 \\
\hline M.N. of Prostate (185) & 26 & 24.0 & 6 & 4.6 & 2 & 3.0 & 0 & 2.5 & 1.5 & 3.4 & $>0.97$ \\
\hline M.N. of Brain (|S|-2) & 10 & 12.2 & 4 & 2.1 & 2 & 1.1 & o & 0.6 & 2.2 & 2.4 & 0.56 \\
\hline $\begin{array}{l}\text { Lymphosarcoms anc RetIculum } \\
\text { Cell Sarcoma }(\approx 00)\end{array}$ & 12 & 11.6 & 2 & 1.6 & 1 & 1.1 & 0 & 0.7 & 1.5 & 2.6 & 0.83 \\
\hline Hodgkins Disease (201) & 4 & 4.8 & 2 & 0.8 & 0 & 0. & 0 & 0.1 & 1.4 & 1.7 & 0.59 \\
\hline Myelold Leukemla (205) & 7 & 5.7 & 0 & 1.5 & 1 & 0.6 & 0 & 0.3 & 1.6 & 2.5 & 0.71 \\
\hline Other Leukemia $(: 04,206-7)$ & 6 & 5.2 & 0 & 0.5 & 0 & 0.2 & 0 & 0.1 & 0.6 & 1.5 & 0.75 \\
\hline Multiple Myeloma (203) & 4 & 5.1 & 0 & 0.8 & 0 & 0.6 & 3 & 0.5 & 11.2 & 3.3 & $0.006^{\mathrm{d}}$ \\
\hline $\begin{array}{l}\text { Other M. M. of Lynphatic and } \\
\text { Hema topoletic IIssue (202, 208-9) }\end{array}$ & 5 & 4.5 & 0 & 0.4 & 0 & 0.1 & 0 & 0.0 & 0.6 & 1.0 & 0.68 \\
\hline All other M.N. & 56 & 52.9 & 8 & 8.2 & 3 & 4 & 2 & 3.5 & 1.9 & 2.7 & 0.88 \\
\hline All Non-Cancer Causes & 1377 & 1363.1 & 197 & 205.1 & 115 & 115.1 & 70 & 75.7 & 2.4 & 2.5 & 0.80 \\
\hline
\end{tabular}

Expected deaths are calculated from the experience of all workers in the exposure study. allowing for age. calendar year, occupation, and employmeat status.

bThe significance levels are for a one-tafled test and are calculated using a narmal approximation. For M.M. of the pancreas, cther digestive organs. and prostate, the true levels are somewhat larger than those given. ICD codes.

This probability calculated exactly.

ESee Radiation Resfarch 79: 122 for complete detalls. 